\title{
SV40: A human pathogen?
}

\author{
Robert L. Garcea* \\ Section of Pediatric Hematology/Oncology/Bone \\ Marrow Transplantation, Department of Pediatrics, \\ University of Colorado School of Medicine, Denver, \\ CO 80262, USA
}

Over the past eight years an increasing number of investigators have found SV40 genomic sequences in a variety of human samples, both malignant and normal. Tumor types recurrently reported as SV40-positive include choroid plexus neoplasms, ependymomas, osteosarcomas, and mesotheliomas. Nonetheless, considerable skepticism that SV40 is a human pathogen still prevails. More constructively, the study of SV40 in humans has renewed interest in the related BK and JC viruses and their role in human disease. New questions now must be addressed. In particular, seroepidemiologic studies utilizing reagents that distinguish SV40, BKV, and JCV immune responses would be a logical next step for independently assessing viral prevalence. Also, prospective studies of select patient groups using optimized detection methods might determine whether SV40 is associated with human oncogenesis in particular circumstances. The importance of such research is underscored by the potential to prevent human polyomavirus infections, and possible associated malignancy, through immunization of high risk populations.

\section{Introduction}

Simian virus 40 (SV40) has been a model experimental system for the study of cell transformation and tumorigenesis since its discovery in the late 1950s as a contaminant of the Salk polio vaccine. During the 1970s and 1980s, Southern hybridization techniques coupled with viral T(tumor)-antigen immunohistochemistry and electron microscopic visualization of viral particles, suggested that SV40 may be present in human malignancies (e.g. [1,7]). However, these data were criticized because of technologic problems such as DNA cross-hybridization, cell culture contamination with SV40, and T-antigen immunologic reagents that

*Address for correspondence: UCHSC Box C229, 4200 East Ninth Ave., Denver, CO 80262, USA. Tel.: +1 303315 3247; Fax: +1 303315 3244; E-mail: bob.garcea@uchsc.edu. cross-reacted with proteins of the recently discovered human JC and BK viruses.

With the advent of polymerase chain reaction (PCR) detection methods, a resurgence of investigations again found SV40 in a variety of human neoplasms as well as normal tissues. Bergsagel et al. [2] utilized PCR primers directed at the $\mathrm{Rb}$ binding site of large $\mathrm{T}$ antigen to search for BKV and JCV viruses in rare human childhood brain tumors, e.g. choroid plexus neoplasms and ependymomas. These tumors were investigated based upon rodent animal models where similar neoplasms developed as a consequence of viral inoculation, and from a transgenic mouse model expressing SV40 large T-antigen from the native viral promoter, whose phenotype was the development of choroid plexus tumors. Unexpectedly, Bergsagel et al. found SV40 instead of BKV and JCV, as evidenced by DNA sequencing and restriction endonuclease digestion of PCR amplified DNA from these tumors, thus prompting further searches for SV40 utilizing the "Bergsagel" primers.

Since 1992 numerous reports of SV40-like virus sequences in human neoplasms have been reported using PCR technology. In addition to choroid plexus neoplasms and ependymomas, mesotheliomas and bone tumors have been the focus of many of these reports. Carbone et al. [3] studied mesotheliomas based upon rodent animal models indicating that these tumors could be readily induced by appropriate virus inoculation. Using the Bergsagel primers, SV40-like sequences were found in mesotheliomas, and this observation has been subsequently verified in many laboratories and the further study of the T-ag protein in complex with cellular proteins has been pursued in detail. Detection of SV40like sequences in bone tumors was uncovered during a large survery of tumor DNAs for viral sequences [4]. Recently, Mendoza et al. [13] detected SV40 by Southern blot hybridization in osteosarcoma tumor DNA, thus extending these PCR observations.

Aside from choroid plexus neoplasms, ependymomas, bone tumors, and mesotheliomas, SV40-like sequences have been sporadically found by PCR methods in a variety of human tissues and neoplasms including peripheral blood, semen, papillary thyroid cancer and 
brain tumors of other histologies (e.g. $[6,12,14])$. However, reproducibility of these findings has been inconsistent. Perhaps encouraged by the SV40 data, other investigators have detected JCV in colon cancer [9] and medulloblastomas [8], and BKV in neuroblastoma [5]. These are ubiquitous human polyomaviruses however, and a cause-effect relationship with tumor development remains to be established.

PCR detection of SV40 sequences in tumor tissue has been less than facile [10]. Commonly many PCR cycles (40-60) are required. This difficulty in amplification has been attributed to inefficiencies in extracting tumor DNA from archival paraffin-embedded tissue samples. Also, DNA isolation from the samples is a potential problem, and commercial plasmid isolation kits have been found inferior to direct precipitation of total DNA. Recently, the possibility that supercoiled viral genomes resistant to PCR amplification can be overcome by topoisomerase I relaxation has been raised [9]. BKV and JCV DNA sequences are very similar to those of SV40 in the regions most frequently amplified, and concurrent presence of $\mathrm{BKV} / \mathrm{JCV}$ must be assayed as well as SV40. Immunohistochemical identification of T-antigen remains problematic because current antibody reagents do not adequately distinguish between SV40/BKV/JCV T-antigens, emphasizing the importance of assaying for all three viruses by PCR before attributing T-antigen staining to a specific agent.

Despite technological hurdles and questions concerning specificity of detection and sources of PCR contamination, many independent observations suggest the validity of SV40 identification. First, direct DNA sequencing of the PCR-amplified products distinguishes them from BKV and JCV [2]. Second, PCR amplification of other regions of the viral genome have uncovered remarkable specificities for SV40 [11]. In amplifying the viral promoter/enhancer region for example, a single 72 base pair repeat element was found for SV40 in the choroid plexus samples. This single enhancer element is characteristic of SV40 isolated directly from primates. This element quickly undergoes duplication when the virus is propagated in tissue culture, presumeably because the duplication provides a growth advantage. Thus, the single 72 base pair repeat effectively controls for laboratory strain contamination in the PCR assay. Also, PCR amplification of sequences at the carboxy terminus of large T-antigen has revealed specific base changes in the viral "hostrange" domain, so termed because of its influence on virus growth in different cell types. The Southern blot detection of SV40 sequences in osteosarcomas effec- tively eliminates the issue of PCR contamination [13]. The subcellular immunohistochemical localization p53 in T-antigen containing tumors is quite characteristic, with a "chunky" cytoplasmic accumulation that may be related to its specific interaction with T-antigen [5]. Finally, authentic SV40 virus has been recovered from a human choroid plexus tumor [11].

Difficulty in easily amplifying SV40 sequences has raised skepticism about the findings [16]. These technical difficulties may have also generated a lack of reproducibility between laboratories enhancing the skepticism. Calculations of viral copy numbers have given estimates of 1 viral genome per 10 tumor cells, confounding explanations for a cause-effect relation to tumor development and raising issues of PCR contamination. Epidemiologic studies have failed to confirm an association of increased tumor incidence in recipients of SV40-contaminated polio vaccines [15,17]. However, these studies are based upon narrow assumptions and do not address whether SV40 may have been endemic in humans before polio vaccination, whether the virus could be horizontally or vertically transmitted from vaccine recipients, or whether specific subsets of immunocompromised individuals might be more susceptible to tumor development.

Animal models suggest that immunologic status is a powerful factor in oncogenesis by polyomavirus. In addition, genetic predisposition to cancer as found in the Li-Fraumeni families also suggests that the pathologic target for these viruses may involve unique subsets of individuals [2]. Tissue tropism of these viruses is also significant, and correlations between human cancers and those induced in laboratory animals appears strong. Geographic difference in viral prevalence may also affect the likelihood of infection at critical windows of susceptibility. Mechanisms of cause-effect remain elusive for the more ubiquitous BKV and JCV. However the SV40 T-antigen has been extensively characterized and is recognized as a potent immortalizing protein. Unambiguous detection of SV40 T-antigen expression would strongly suggest at least a co-carcinogenic role in tumor development.

The era of PCR screening for SV40 sequences in human tissues now needs to progress to another level of inquiry. Although Southern hybridization would be desirable, viral copy number and tissue availabiltiy limits this approach. Serologic assays capable of distinguishing BKV, JCV, and SV40 immune responses would be invaluable in clarifying issues of prevalence. Specific patient groups (e.g. Li-Fraumeni) and tumor subtypes (e.g. osteosarcomas) also deserve special at- 
tention since they have a strong biologic basis for viral co-carcinogenesis. Thus, the combination of a specific serologic screen with improved PCR methodologies directed at defined patient populations in a prospective manner appears to be the next step in resolving the relevance of polyomaviruses, including SV40, in human tumor development. The viral T-antigens of all these viruses have the potential for being co-carcinogens and, if so, preventing infection would become a potentially powerful avenue for cancer prevention.

\section{Acknowledgments}

I would like to thank Janet Butel, John Lednicky, David Malkin, and Michele Carbone for their collaboration through the years. I apologize that space limited a complete bibliographic citing of all related work.

\section{References}

[1] G.O. Bastian, Papova-like virus particles in a human brain tumor, Lab. Invest. 25 (1971), 169-175.

[2] D.J. Bergsagel, M.J. Finegold, J.S. Butel, W.J. Kupsky and R.L. Garcea, DNA sequences similar to those of simian virus 40 in ependymomas and choroid plexus tumors of childhood, $N$ Engl J Med 326 (1992), 988-993.

[3] M. Carbone, H.I. Pass, P. Rizzo, M. Marinetti, M. Di Muzio, D.J. New, A.S. Levine and A. Procopio, Simian virus 40-like DNA sequences in human pleural mesothelioma, Oncogene 9 (1994), 1781-1790.

[4] M. Carbone, P. Rizzo, A. Procopio, M. Giuliano, H.I. Pass, M.C. Gebhardt, C. Mangham, M. Hansen, D.F. Malkin, G. Bushart, F. Pompetti, P. Picci, A.S. Levine, J.D. Bergsagel and R.L. Garcea, SV40-like sequences in human bone tumors, Oncogene 13 (1996), 527-535.

[5] T. Flaegstad, P.A. Andresen, J.I. Johnsen, S.K. Asomani, G.-E. Jørgensen, S. Vignarajan, A. Kjuul, P. Kogner and T. Traavik, A possible contributory role of BK virus infection in neurob- lastoma development, Cancer Res. 59 (1999), 1160-1163.

[6] H. Huang, R. Reis, Y. Yonekawa, J.M. Lopes, P. Kleihues and $\mathrm{H}$. Ohgaki, Identification in human brain tumors of DNA sequences specific for SV40 large T antigen, Brain Path. 9 (1999), 33-44.

[7] P. Krieg, E. Amtmann, D. Jonas, H. Fischer, K. Zang and G. Sauer, Episomal simian virus 40 genomes in human brain tumors, Proc Natl Acad Sci USA 78 (1981), 6446-6450.

[8] B. Krynska, L.D. Valle, S. Croul, J. Gordon, C.D. Katsetos, M. Carbone, A. Giordano and K. Khalili, Detection of human neurotropic JC virus DNA sequence and expression of the viral oncogenic protein in pediatric medulloblastomas, Proc. Natl. Acad. Sci. (USA) 96 (1999), 11519-11524.

[9] L. Laghi, A.E. Randolph, D.P. Chauhan, G. Marra, E.O. Major, J.V. Neel and C.R. Boland, JC virus DNA is present in the mucosa of the human colon and in colorectal cancers, Proc. Natl. Acad. Sci. (USA) 96 (1999), 7484-7489.

[10] J.A. Lednicky and R.L. Garcea, Detection of SV40 DNA sequences in human tissue, in Methods in Molecular Biology, "SV40 Protocols". Raptis ed., Humana Press Inc., Totowa, NJ, (in press).

[11] J.A. Lednicky, R.L. Garcea, D.J. Bergsagel and J.S. Butel, Natural simian virus 40 strains are present in human choroid plexus and ependymoma tumors, Virology 212 (1995), 710 717.

[12] F. Martini, L. Iaccheri, L. Lazzarin, P. Carinci, A. Corallini, M. Gerosa, P. Iuzzolino, G. Barbanti-Brodano and M. Tognon, SV40 early region and large $\mathrm{T}$ antigen in human brain tumors, peripheral blood cells, and sperm fluids from healthy individuals, Cancer Res. 56 (1996), 4820-4825.

[13] S.M. Mendoza, T. Konishi and C.W. Miller, Integration of SV40 in Human Osteosarcoma DNA, Oncogene (1998), (in press).

[14] F. Pacini, A. Vivaldi, M. Santoro, M. Fedele, A. Fusco, C. Romei, F. Basolo and A. Pinchera, Simian virus 40-like DNA sequences in human papillary thyroid carcinomas, Oncogene 16 (1998), 665-669.

[15] K. Shah and N. Nathanson, Human exposure to SV40: review and comment, Am J Epidemiol 103 (1976), 1-12.

[16] K.V. Shah, Does SV40 infection contribute to the development of human cancers? Rev. Med. Virol. 10 (2000), 31-43.

[17] H.D. Strickler, J.J. Goedart, M. Fleming, W.D. Travis, A.E. Williams, C.S. Rabkin, R.W. Daniel and K.V. Shah, SV40 and pleural mesotheliomas in humans, Cancer Epidem. Biomarkers Prevention 5 (1996), 473-475. 


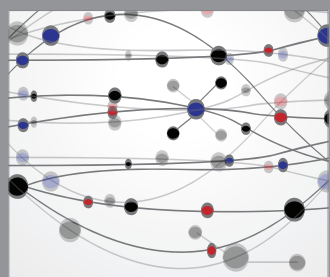

The Scientific World Journal
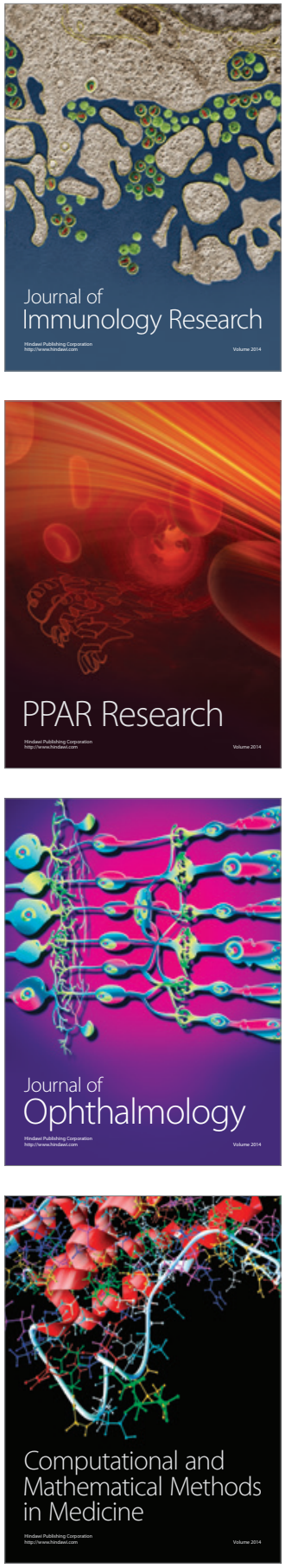

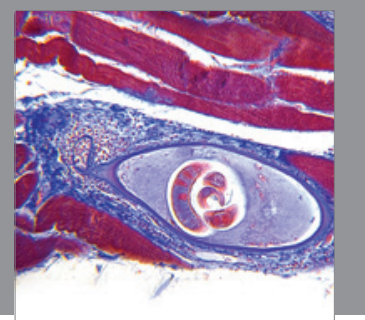

Gastroenterology

Research and Practice
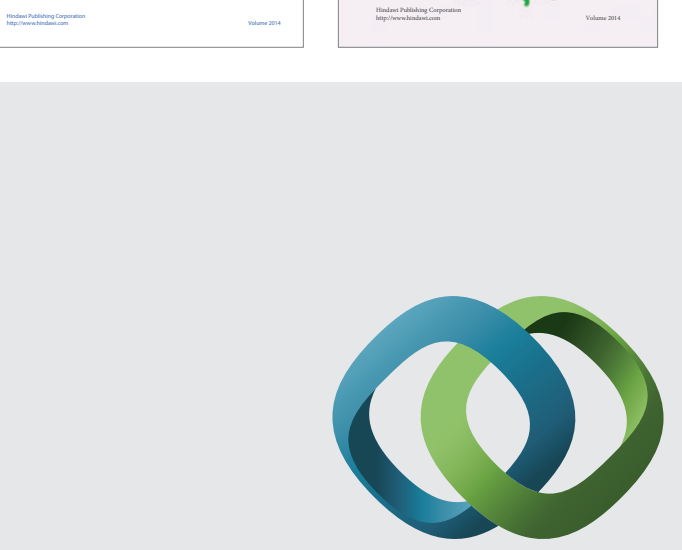

\section{Hindawi}

Submit your manuscripts at

http://www.hindawi.com
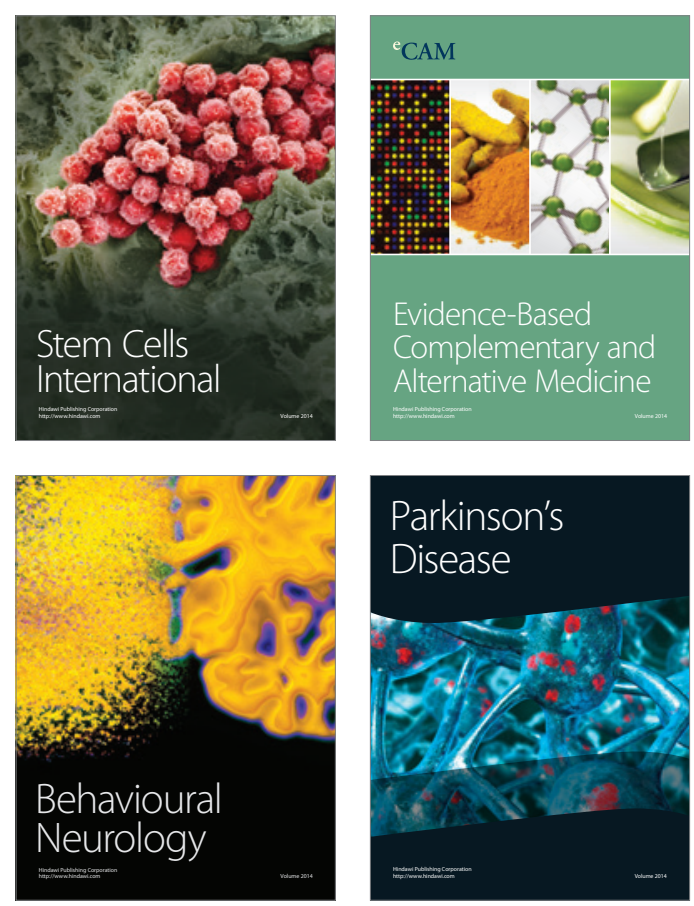

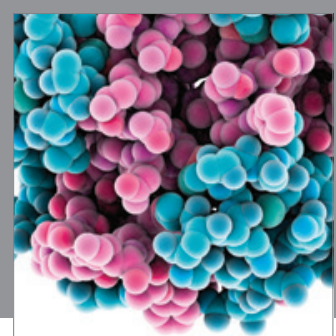

Journal of
Diabetes Research

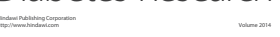

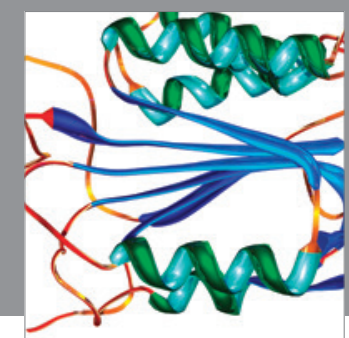

Disease Markers
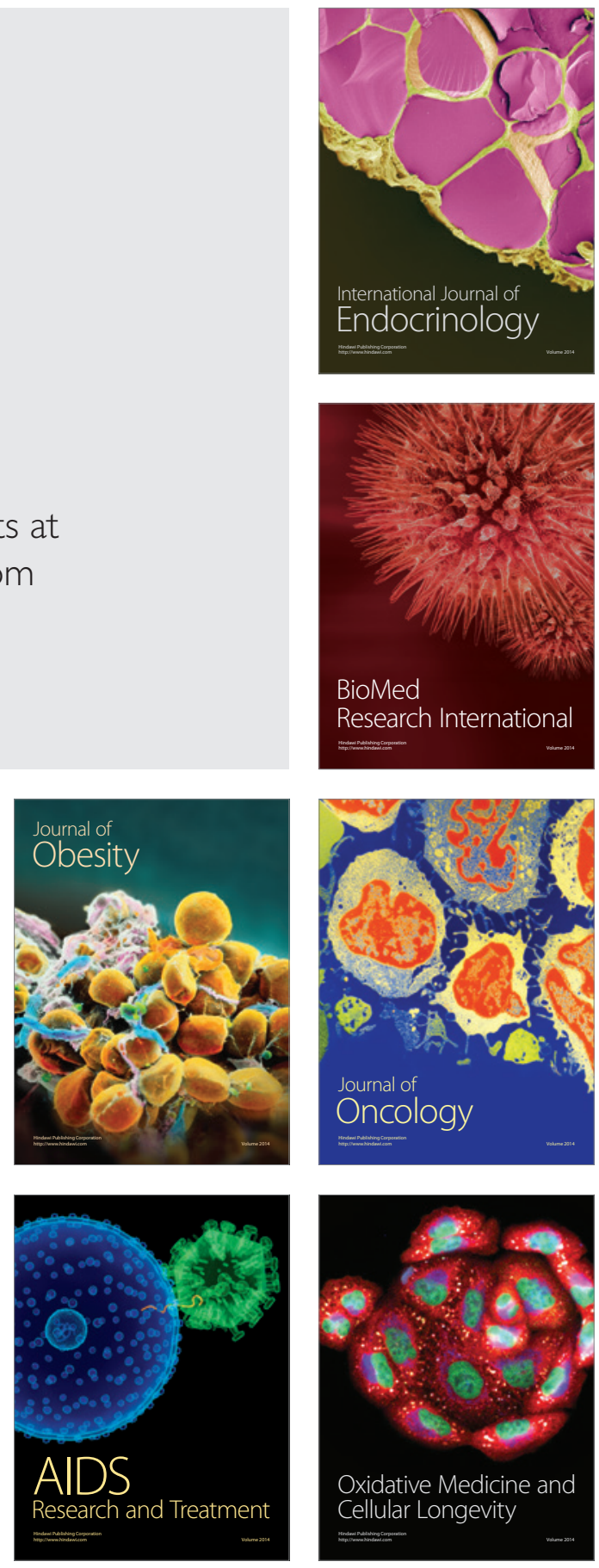